\title{
Itinera Petri. Биохроника Петра Великого - день за днем (1672-1725)
}

\section{Itinera Petri: A Day by Day Bio-Chronicle of Peter the Great (1672-1725)}

\author{
Е. В. Анисимов \\ Национальный исследовательский университет - Высшая школа экономики \\ (Санкт-Петербург) \\ Evgenii V. Anisimov \\ National Research University - Higher School of Economics (St. Petersburg) \\ eanisimov@hse.ru
}

\begin{abstract}
:
This article is devoted to the electronic project Itinera Petri: A Day-by-Day Bio-Chronicle of Peter the Great (1672-1725). This is an online database representing the life of Peter I in the form of electronic records, each of which corresponds to one day in the life of the monarch. The uniform presentation of the material follows a fixed format with the goal of separating facts from interpretations. The database is equipped with a searchable interface organized according to different parameters (including by toponyms and personal names).
\end{abstract}

Keywords:

Peter I; bio-chronicle; digital humanities

\section{История проекта}

“Биохроникой” можно назвать и незамысловатую таблицу с датами (такие часто встречаются в биографиях выдающихся людей) и многотомные издания, в которых, помимо биографической канвы, публикуются документы, относящиеся к жизни героя. Такой биохроникой является 12-томная Биохроника В. И. Ленина плод работы десятков людей - сотрудников бывшего Института марксизмаленинизма. ${ }^{\prime}$ Немало издано писательских Летописей жизни и творчества. Наиболее значительной из них является работа М.А. Цявловского о А.С. Пушкине. ${ }^{2}$ Существуют и другие подобные издания, посвященные А. И. Герцену, И. С. Тургеневу, М. Ю. Лермонтову, Ф. М. Достоевскому, М. Горькому, С. А. Есенину, Ф. А. Абрамову и т.д. Из “неписательских” биохроник отмечу биохроники жизни П.А. Столыпина, А.Ф. Кони. Из западных произведений этого ряда

\footnotetext{
${ }^{1}$ Институт марксизма-ленинизма при ЦКПСС. Владимир Ильич Ленин: биографическая хроника, 1870-1924 [под общей редакцией Г. Н. Голикова ... et al.] 12 тт. (Москва: Политиздат, 1970). (Institut marksizma-leninizma pri TsKPSS, Vladimir Il'ich Lenin: biograficheskaia khronika, 1870-1924 [pod obshcheĭ redaktsieĭ G. N. Golikova ... et al.], 12 vols. (Moscow: Politizdat, 1970).

2 Летопись жизни и творчества Александра Пушкина: в четырех томах [составитель М. А. Цявловский] (Москва: Изд-во Слово, 1999-2005). (Letopis' zhizni i tvorchestva Aleksandra Pushkina:v chetyrekh tomakh [sostavitel' M. A. Tsiavlovskiī] (Moscow: Izd-vo Slovo, 1999-2005)).
} 
примечательны биохроники Джоржа Вашингтона, Авраама Линкольна, А.А. Бетанкура.

И вот здесь сразу возникает любопытная коллизия, связанная с характером изложения материала. Многие авторы уходят от однообразного, “сухого” изложения материала и (под влиянием многих факторов) переходят к написанию биографии, давая фактам биографии героя собственную интерпретацию. Так, собственно, произошло с выдающимся русским историком М. М. Богословским, который от статьи - краткой биохроники Петра, заказанной ему для Словаря Гранат, перешел к написанию многотомной биографии Петра Великого и создал пять томов, дойдя только до начала XVIII века. ${ }^{3}$ Я же был намерен избежать этого, хотя отказаться от интерпретаций и комментариев невозможно уже в силу того, что информация источников может трактоваться по-разному, что источники могут противоречить друг другу, что всегда есть темные места, требующие пояснения, а, следовательно, интерпретации. Поэтому в работе создан некий единый шаблон, формула подачи материала с тем, чтобы развести факты и собственно интерпретации.

Биохронику Петра Великого $^{4}$ (поначалу в виде карточек) я собирал четыре десятилетия и, наверное, продолжал бы делать и дальше - это занятие, схожее с коллекционированием монет, марок и бабочек, было утехой моих воскресных вечеров, отдохновением от привычной суеты и текущей работы, обычно висевшей над головой лезвием гильотины сроков и обязательств. Но два обстоятельства отвлекли меня от этого сладостного занятия. Первое - мои коллеги, узнав о Биохронике, стали брать у меня справки по конкретному сюжету или дате, что делало мое занятие публичным и давало мне осознание востребованности этого труда профессиональной корпорацией. Поэтому я включил проект в плановое задание по Отделу древней истории Санкт-Петербургского института истории РАН и продолжил его, уже перейдя в Санкт-Петербургский филиал НИУ-ВШЭ. Второе обстоятельство заключалось в том, что ректор НИУ-ВШЭ Я. И. Кузьминов, узнав о моей работе, тотчас предложил свое содействие в ее публикации на электронной Платформе НИУ-ВШЭ. И с этого момента все завертелось. Особенно я благодарен содействию в продвижении проекта со стороны М. М. Юдкевич и Д.Б. Коптюбенко, а также моя безмерная благодарность предназначается программисту, создавшему портал, Игорю Васильеву.

\section{База данных}

“Единицей измерения” информации Биохроники является, условно говоря, привычная нам “карточка" - ее можно представить в виде традиционной библиографической карточки или просто как лист бумаги А-4. Подобная “антропологичность” должна естественным образом войти в сознание гуманитария, привыкшего работать с подобными накопителями информации. Далее уже легко представить себе структуру такой “карточки.”

\footnotetext{
${ }^{3}$ М. М. Богословский, Петр I: материалы для биографии, под ред. В.И. Лебедева. 5 тт. (Москва: Огиз, Гос. социально-экон. изд-во, 1940-48) (М. M. Bogoslovskiĭ, Petr I: materialy dlia biografii, pod red. V.I. Lebedeva. 5 vols. (Moscow: Ogiz, Gos. sotsial'no-èkon. izd-vo, 1940-1948)).

${ }^{4}$ Itinera Petri. Биохроника Петра Великого - день за днем (1672-1725),

https://spb.hse.ru/humart/history/peter/
} 
Итак, сверху вниз на карточке Биохроники дается рубрика: “Дата, день недели (по старому и новому стилю), пасхалии, семейные праздники династии Романовых и государственные праздники.” Это позиция 1. Затем ниже следует позиция 2: "Место пребывания Петра в этот день и его перемещения и деятельность”: поездки, общение с людьми, участие в мероприятиях и т.д. (изложение по возможности близко к тексту документа, с использованием цитирования, с сохранением противоречий источников). Позиция 3. "Письма и бумаги Петра”: это перечень содержания писем, указов, манифестов, резолюций и прочие материалы личной переписки Петра, с указанием утраченных или возможно существовавших документов. Принцип здесь такой: вначале - адресат, далее - тип документа, краткое содержание, цитата (при необходимости). Позиция 4. "Разные письма и бумаги": письма к Петру и письма его сподвижников между собой, которые касаются Петра и его действий. Наконец, следует последняя 5-ая позиция - “Комментарий”: справки, уточнения, отсылки к другим датам, историография вопроса (преимущественно по спорным вопросам, когда есть у разных авторов разная интерпретация событий с отсылкой к соответствующим монографиям и статьям; отсылка дается также там, где читатель может найти более пространное изложение событий). Наконец, в той же рубрике "Комментарии" я даю свои интерпретации и суждения по поводу рассматриваемых сюжетов. Сразу отмечу, что они наверняка субъективны и поэтому они отделены от основного контента и необязательны для чтения, ибо цель Биохроники - иная: дать объективную, проверяемую всеми информацию о событиях. Я старался следовать старому профессиональному принципу: "Нет источника - нет факта." Поэтому вся информация (за исключением моих домыслов) снабжена сносками, подобно тому, как это всегда делается в научной литературе. Отдельно есть “Список источников и литературы" и “Список сокращений.” Источниками информации для Биохроники послужили самые разнообразные материалы: публикации исторического источников, архивный материал главных архивов страны по этой тематике, научные исследования других авторов, основанные на источниках (преимущественно архивных), т.е. учтены результаты изысканий ученых, выявивших материалы, которые можно использовать для Биохроники (естественно, со сносками). К корпусу Биохроники приложена библиография из нескольких сотен названий источников и содержащая необходимую информацию о литературе по разным вопросам, а также указатели. Если исходить из критерия “факта” как зафиксированного источниками события жизнедеятельности и переписки, применявшихся к анализу материалы биохроники Ленина или Линкольна, то в нашем случае зафиксировано около 40 тысяч фактов биографии Петра Великого, что позволяет исследователям и всем интересующимся историей получить исчерпывающую информацию касательно истории личности Петра Великого.

Вот как выглядит “карточка” в моем компьютере в готовом виде для переноса на “карточку” сайта:

20/31.01.1717, вс.

П. в Амстердаме. 
Письма и бумаги П.: 1. Резолюция о выдаче жалования гофмейстерине А. Е. Матвеевой в Курляндии; 2. Запись расходов: выдано генерал-фискалу Иосифу Шпинолю 50 червонцев. ${ }^{* 6}$

Разные письма и бумаги: 1. Кн. П. М. Голицын - П. из Ростока об освобождении пришедших из Швеции двух судов с железом, о прибытии галер с лесом и припасами и плотников, просит “о повелительном касательно их указе”; 2. Б. П. Шереметев - П.: сообщает, что получил из Амстердама его указ 05.01 о рождении сына, поздравляет с этим событием; что получил от Р. Х. Боура сообщение о смерти 19.12 К. Э. Ренне; что получил указ П. из Амстердама от 22.12, “дабы иметь старание о привозных галерных припасах и мундире.”

Комментарий.

* Возможно, что эта запись связана с посылкой Иосифа Шпиноля в Мекленбург для расследования жалоб на поведение русских солдат и офищеров. П. писал герцогу Карлу-Леопольду, “дабы и он с сим посланным благоволил обще разсмотреть о тех обидах, буде оне подлинно были."

Как происходила работа над проектом? Составленная мною “карточка" вносилась на электронную платформу НИУ Высшей школы экономики в Редакторский интерфейс проекта. Этот раздел называется "Редактирование карточки." Там четыре окна, созданных согласно структуре проекта: “Карточка," “Топонимы," “Персоналии," “Названия." Окно "Карточка” - основное. Главное окно - дата. В это окно переносилась вся информация с указанной выше карточки. Одновременно на этой карточке заполнялись указанные там окна: “Топонимы,” “Персоны," “Названия."

\footnotetext{
${ }^{5}$ Комиссия по изданию писем и бумаг императора Петра Великого / Научно-исторический архив СанктПетербургского института истории РАН. Фонд 270. ОП. 1. Д. 84. Л. 72. (Komissiia po izdaniiu pisem i bumag imperatora Petra Velikogo," Nauchno-istoricheskii arkhiv Sankt-Peterburgskogo instituta istorii RAN. Fond 270, op. 1, d. 84, 1. 72).

${ }^{6}$ Сборник выписок из архивных бумаг о Петре Великом, сост. Г.В. Есипов, т. 1-2 (Москва, 1872), 2: 55 (Sbornik vypisok iz arkhivnykh bumag o Petre Velikom, sost. G. V. Esipov, 2 vols. (Moscow, 1872), 2: 55). ${ }^{7}$ Материаль для истории русского флота, ч. 1-6 (Санкт-Петербург, 1865-1877), 2: 182 (Materialy dlia istorii russkogo flota, ch. 1-6 (St. Petersburg, 1865-1872), 2: 182).

${ }^{8}$ Б. П. Шереметев, Письма к государю императору Петру Великому от генерал-фельдмаршала, тайного советника мальтийскаго, с. апостола Андрея, Белого орла и прусского ордена кавалера, графа Бориса Петровича Шереметева, ч. 1-4 (Москва, 1778-1779)), 1: 269-274. (B. P. Sheremetev, Pis'ma k gosudariu imperatoru Petru Velikomu ot generala-fel'dmarshala, tainogo sovetnika mal 'tiiskogo, s apostola Andreia, Belogo orla i prusskogo ordena kavalera, grafa Borisa Petrovicha Sheremeteva, ch. 1-4 (Moscow, 1778-1779), 1: 269-274).

${ }^{9}$ И. И. Голиков. Дополнения к “Деяниям Петра Великого,” т. 1-18 (Москва, 1790-1795), 6: 203. (I. I. Golikov, Dopolneniia k 'Deianiiam Petra Velikogo,' 18 vols. (Moscow, 1790-1795), 6: 203).
} 


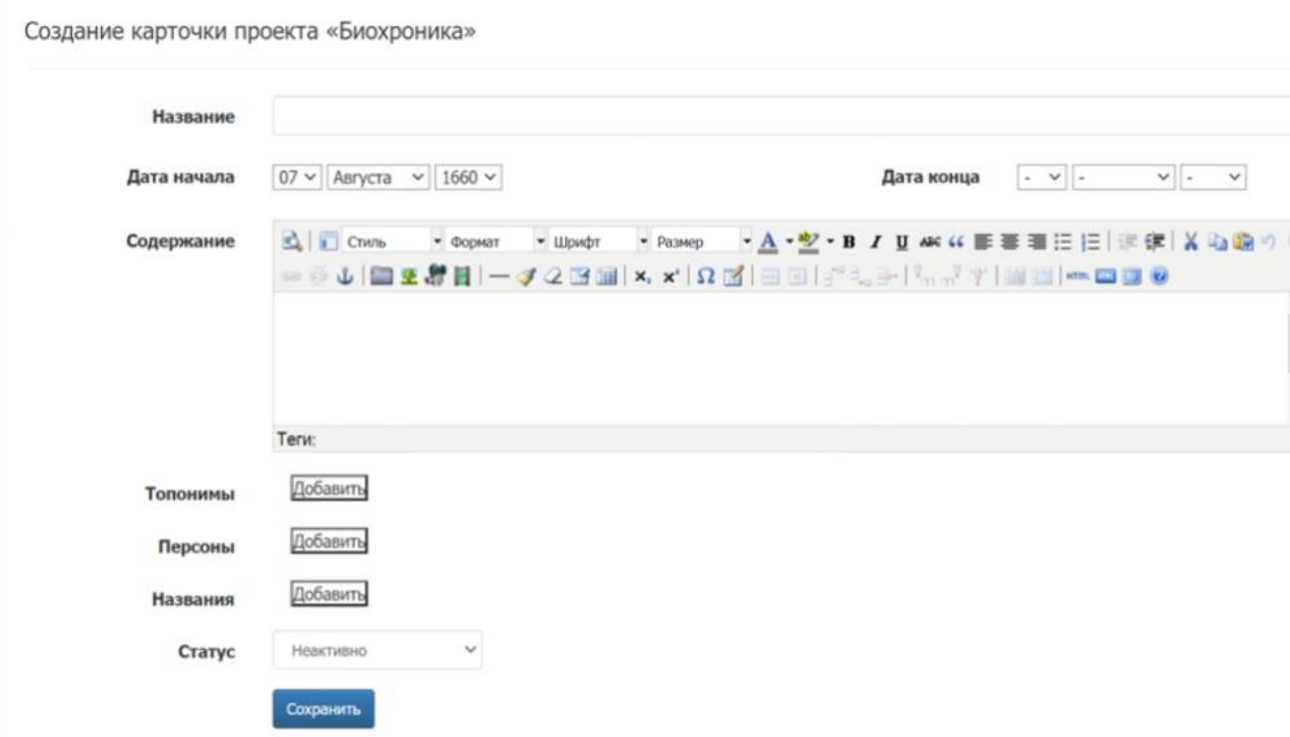

Если обратиться к моей карточке, то вносились: дата, содержание (“П. в Амстердаме”), “Письма и бумаги," “Разные письма и бумаги,” “Комментарий,” а также топонимы (“Амстердам,” “Курляндия” и т.д.), персоналии, названия. Если таких топонимов не было в памяти машины, то открывалось дополнительное окно, куда редактор вносил этот топоним и в следующий раз этот топоним автоматически попадал в раздел “Топонимы” карточки. Также было и с другими окнами, в которые вносились персоналии и названия (кораблей, церквей, книг и др.). В законченном виде карточка выглядела так.

Редактирование карточки проекта «Биохроника»

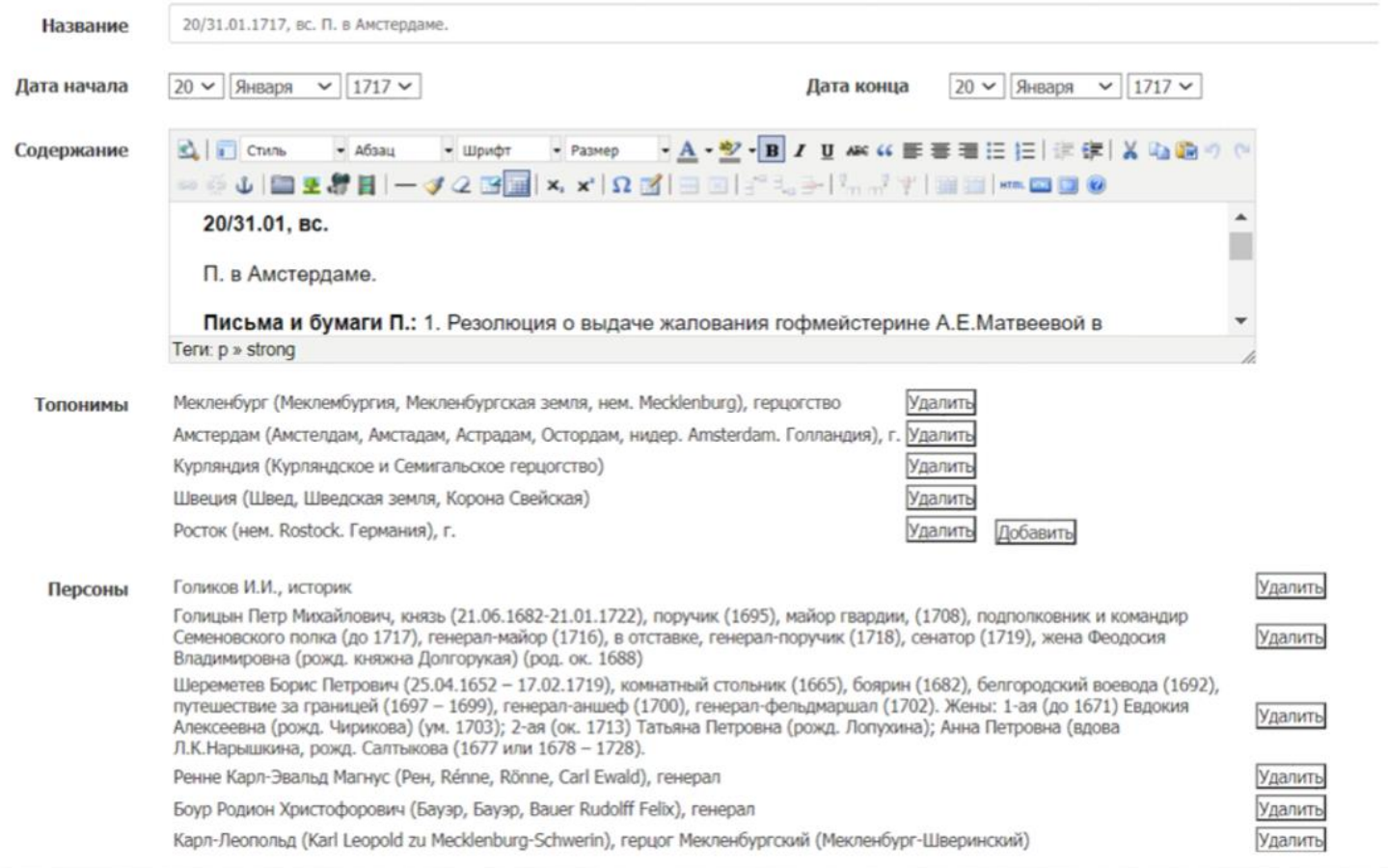


Для посетителей сайта вход открыт из общей ссылки-адреса в интернете: https://spb.hse.ru/humart/history/peter/. На “лицевой странице” шесть позиций для поиска: “Общий поиск” (по датам, в диапазоне с 1660 до 1740 г.), “Поиск по топонимам,” “Поиск по персонам,” “Поиск по названиям,” “Список сокращений,” "Источники и литература."

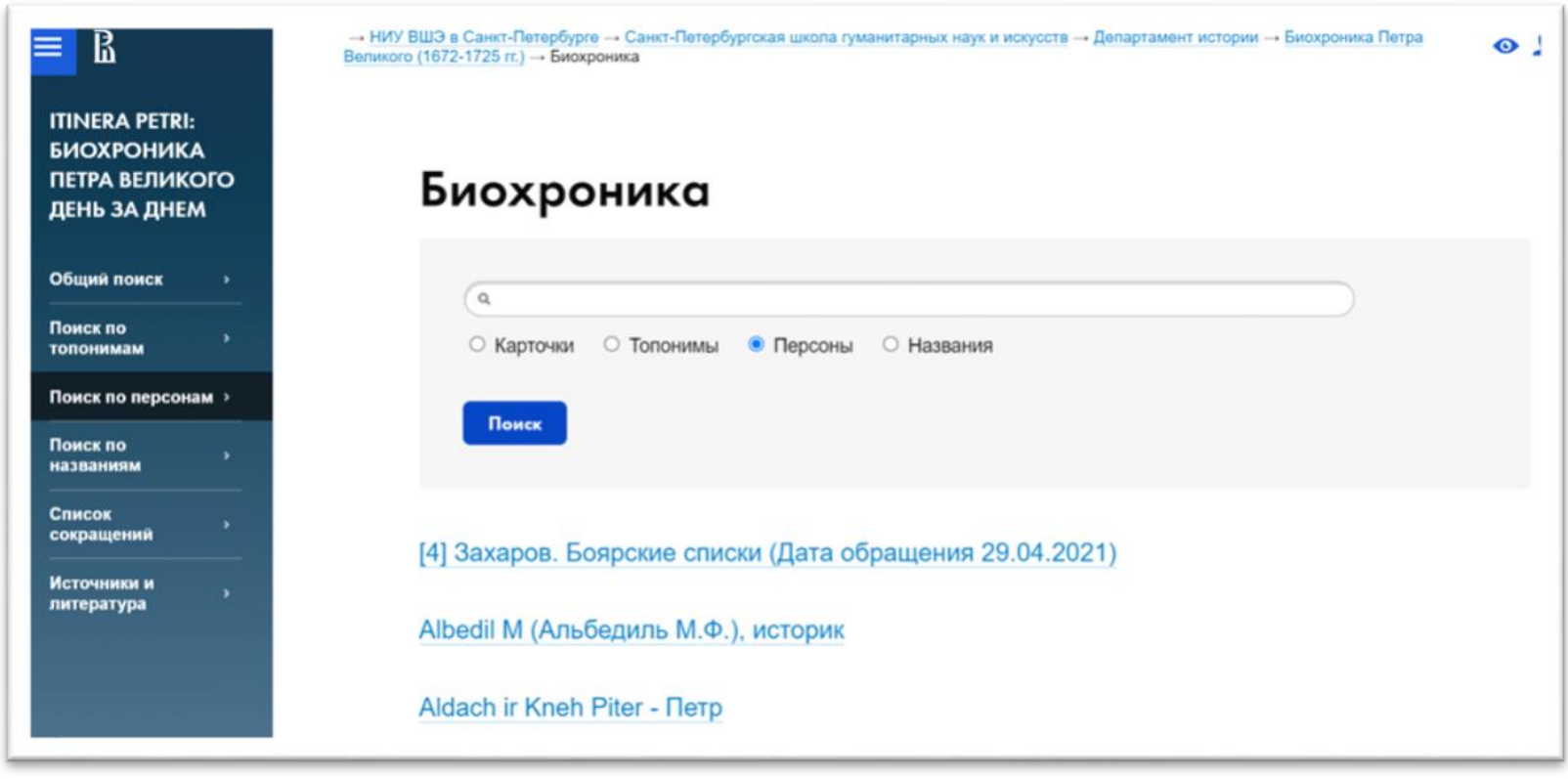

При заполнении соответствующего окна, у читателя на экране появляется вся запрошенная им информация. Однако вход читателю “за кулисы,” как это есть в Википедии, закрыт - только у редактора есть ключ к редактированию карточек. В этом особенность проекта - не дать возможности испортить материал Биохроники людям некомпетентным, случайным, ибо я стремился обеспечить справочнику полную достоверность и проверяемость.

Как раз огромным достоинством всего проекта (в отличие от публикации справочника на бумаге в виде книги) является то, что редакторский интерфейс позволяет вносить в Биохронику исправления, дополнения по содержанию карточки, заводить новую карточку или удалять ошибочную. Во вводной части проекта я призвал своих читателей участвовать в проекте и присылать мне свои замечания, исправления, дополнения. И почти сразу же такие письма пошли со всех концов мира, от ученых, которые присылали мне свои замечания. Я уточняю их, проверяю и вношу в Биохронику. Моим обязательным правилом является толерантность - дать ту точку зрения, которой придерживается автор поправки и обязательно указать имя автора дополнений или исправлений и внести его имя в раздел “Персоналии." В этом отражается сверхзадача проекта - сделать Биохронику общим, коллективным трудом.

\section{Будущее}

Как известно, будущее всегда в тумане неизвестного. Касаясь Биохроники, можно сказать, что она будет пополняться новыми фактами как мной, так и моими коллегами, которые имеют со мной связь. Я являюсь редактором портала. Не будет меня - появится другой человек, который будет вести портал и так может 
быть бесконечно долго. Технические возможности портала позволяют его развивать. Нужно иметь в виду, что “карточка” не имеет пределов, она уходит в бесконечность и к ней можно прикреплять целые книги, статьи, карты, планы, кино- фото-, аудио- документы. Возможности интернетных расширений огромны. Появятся новые интерфейсы по разным аспектам истории, археологии и других дисциплин, они могут быть параллельны интерфейсу Биохроники и будут связаны с ней, и вдруг между самыми разнообразными комплексами информации будет возникать некая, крайне важная, неведомая нам еще связь. Она вдруг позволит нам постичь то, что неведомо, непонятно. Я обычно привожу такой пример. Както раз замечательный историк Н. Я. Эйдельман подошел ко мне в зале архива и показал письма Петра III к Екатерине II, написанные в тот момент, когда она устроила против мужа переворот. Все эти письма уже давно опубликованы, содержание их знакомо всем. Но Эйдельман говорил: “Посмотрите, как это написано, на этот почерк, бумагу. Боже мой, тут есть какая-то информация, которую мы пока считать не можем! А ведь придут новые люди и считают, снимут новую информацию!" И это так! Этот снятый материал будет вербализирован (а может это будет излишним) и введен в ареал науки. Кто бы мог подумать 100 лет назад, что в археологии будут применяться дендрохронология, рентген, генетика и т.д. Мне кажется, что современная наука открывает новые возможности, о которых мы и не догадываемся. Они позволяют нам понимать прошлое глубже, видеть дальше, чувствовать лучше и еще больше наслаждаться жизнью в науке. Пусть моя Биохроника будет маленьким кирпичиком в создании нового здания науки. 